\title{
Isolation and Identification of Canthaxanthin from Micrococcus roseus
}

\author{
J. J. COONEY, H. W. MARKS, JR., ${ }^{1}$ AND ANNE M. SMITH ${ }^{1}$ \\ Department of Biology, University of Dayton, Dayton, Ohio, and Department of Biological Sciences.
} Loyola University, New Orleans, Louisiana

Received for publication 7 April 1966

\begin{abstract}
CoONey, J. J. (University of Dayton, Dayton, Ohio), H. W. MARKS, JR., AND ANNE M. SMITH. Isolation and identification of canthaxanthin from Micrococcus roseus. J. Bacteriol. 92:342-345. 1966.-The principal colored carotenoid of Micrococcus roseus was purified by solvent partitioning followed by column and thinlayer chromatography. Absorption spectra, partition coefficients, and infrared spectra suggested that the pigment was a diketo derivative of $\beta$-carotene. The pigment was subjected to reduction, and the reduced pigment was subsequently dehydrated. Spectral data and partition coefficients of these derivatives indicated that the original pigment was canthaxanthin $\left(4^{\prime}, 4^{\prime}\right.$-diketo- $\beta$-carotene $)$. The pigment was an all-trans isomer; it does not exist as an ester in $M$. roseus. Canthaxanthin has not previously been identified as a bacterial pigment.
\end{abstract}

Carotenoid pigments occur in a wide variety of chemosynthetic and photosynthetic microorganisms. The pigments of gram-positive cocci reported to date are primarily carotenoids, but many of the pigments have not been identified. When Micrococcus roseus was cultured on the surface of complex media or in a defined medium, the cell mass appeared orange-pink. In the presence of diphenylamine, pigment production decreased only $27 \%$, suggesting that xanthophylls rather than carotenes constitute the major class of pigments (1). This paper describes the isolation and identification of canthaxanthin, the principal colored carotenoid of $M$. roseus.

\section{Materials AND Methods}

$M$. roseus ATCC 516 was cultured on the surface of stock culture agar in Kolle flasks. Flasks were incubated at $25 \mathrm{C}$ for 5 to 7 days. Cells were rinsed from the surface of the agar with distilled water and washed three times with distilled water. Washed cells were extracted twice with absolute methanol; during each extraction, the suspension was agitated at room temperature for $30 \mathrm{~min}$. The cell pellet which remained after the second extraction was colorless. In early experiments, the pooled methanol extracts were saponified for $30 \mathrm{~min}$ at $65 \mathrm{C}$ with $6 \%(\mathrm{w} / \mathrm{v}) \mathrm{KOH}$, but in later experiments this step was omitted without altering the characteristics of the pigment. Throughout the work, pigments were stored in the dark under nitrogen.

1 Present address: Louisiana State University School of Medicine, New Orleans.
Sufficient distilled water was added to the extract to dilute the methanol to $90 \%(\mathrm{v} / \mathrm{v})$. This solution was partitioned against petroleum ether (boiling point, 30 to $60 \mathrm{C}$ ), with the addition of $\mathrm{Na}_{2} \mathrm{SO}_{4}$ or a saturated aqueous $\mathrm{NaCl}$ solution to facilitate phase separation. The extraction was repeated (usually three times) until the ether phase was colorless. Glassware with Teflon stopcocks was used throughout to avoid contamination of pigments with silicones which interfered with chromatography. The pooled epiphase, which contained the bulk of the colored material, was dried over several portions of anhydrous $\mathrm{Na}_{2} \mathrm{SO}_{4}$, and the petroleum ether was evaporated undes a stream of nitrogen.

The residual red oil was dissolved in a small quantity of anhydrous diethyl ether and applits to the surface of a column ( 2.5 by $8 \mathrm{~cm}$ ) of silica gel G. $A$ broad $(1.5 \mathrm{~cm})$ orange band (fraction I) was eluted with diethyl ether, and after this a narrow $(0.2 \mathrm{~cm})$ yellow band (fraction II) was eluted with methanol. Subsequent analyses were confined to fraction $I$.

The ether was evaporated from fraction I under a stream of nitrogen. The residue was dissolved in $\mathbf{C S}_{2}$ and applied to thin-layer chromatography plates coated with $\mathrm{CaCO}_{3}$ (low in alkali; Matheson, Coleman and Bell, East Rutherford, N.J.). Plates were developed in benzene-petroleum ether $(3: 2, \mathrm{v} / \mathrm{v})$. Pigmented areas were scraped from the plates, and the pigments were eluted from the adsorbent with benzene.

Absorption spectra were determined in spectroquality solvents. Partition coefficients were determined in a hexane-95\% methanol system according to the method of Petracek and Zechmeister (14). Infrared spectra were determined in $\mathrm{CS}_{2}$ and in $\mathrm{CHCl}_{3}$. 
Carbonyl groups were reduced according to Krinsky and Goldsmith (12) by dissolving the pigment in $95 \%$ ethyl alcohol and adding a few crystals of $\mathrm{NaBH}_{4}$. The solution was stored under nitrogen at $4 \mathrm{C}$ overnight; it was then chromatographed on $\mathrm{CaCO}_{3}$ plates; the principal spot was eluted as before.

After reduction, some samples were dehydrated by treatment with $\mathrm{CHCl}_{3}$ saturated with $\mathrm{HCl}$ gas; the pigment was extracted into petroleum ether and washed three times with distilled water to remove excess $\mathrm{NaBH}_{4}$. The ether extract was dried over $\mathrm{Na}_{2} \mathrm{SO}_{4}$, and the solvent was evaporated with nitrogen. The dried pigment was dissolved in $3.5 \mathrm{ml}$ of $\mathrm{CHCl}_{3}$, and two drops of acid $\mathrm{CHCl}_{3}$ was added. After $15 \mathrm{~min}$, the sample was deacidified by shaking with $5 \%(\mathrm{w} / \mathrm{v})$ $\mathrm{NaHCO}_{3}$ (16). The $\mathrm{CHCl}_{3}$ solution was washed with water and dried over $\mathrm{Na}_{2} \mathrm{SO}_{4}$, and the solvent was evaporated under a stream of nitrogen. The residue was chromatographed on $\mathrm{CaCO}_{3}$ plates and eluted as before.

The method of Curl and Bailey (2) was used to test for 5,6-epoxides; the pigment was dissolved in $3.0 \mathrm{ml}$ of petroleum ether and treated with a drop of ethyl alcoholic $0.05 \mathrm{~N} \mathrm{HCl}$. The presence of a 5-6 epoxide group is indicated by a decrease of 16 to $22 \mathrm{~m} \mu$ in the wavelength of maximal absorbance.

Trans isomers were detected by a decrease of 6 to $8 \mathrm{~m} \mu$ in maximal absorbance after treatment with iodine in hexane in the presence of white light (9).

\section{RESUlTS AND DisCUSSION}

When a diethyl ether solution of the epiphasic pigments was layered over concentrated $\mathrm{HCl}$ or $\mathrm{H}_{2} \mathrm{SO}_{4}$, a blue color was obtained. This reaction is characteristic of carotenoids (10).

Thin-layer chromatography of fraction I resolved three spots (Table 1). Spot 1 has not been isolated in sufficient quantity to permit adequate analysis. Spot 2 was larger than spot 3 and tailed into spot 3. Material from each of these spots was eluted and rechromatographed. Although chromatography was repeated as many as five times, material eluted from spot 2 or spot 3 always gave two spots which corresponded in $R_{F}$ values and relative sizes to the original spots 2 and 3. Material from the two spots was analyzed separately in early experiments, and the data obtained were very similar. From these analyses and from behavior on serial chromatograms, we concluded that spots 2 and 3 represented isomers of a single pigment. Material from spots 2 and 3 was pooled in later experiments. Krinsky and Goldsmith (12) obtained similar results when antheraxanthin was chromatographed on columns of aluminum oxide.

Visible-range absorption spectra of the pigment showed a single broad maximum and were symmetrical (Fig. 1). Absorption maxima in several solvents are given in Table 2 . Spectra with a single broad peak are characteristic of keto
TABLE 1. Characteristics of pigments separated by thin-layer chromatography of fraction I on $\mathrm{CaCO}_{3}$

\begin{tabular}{|c|c|c|c|c|}
\hline \multirow{2}{*}{$\begin{array}{l}\text { Spot } \\
\text { no. } 1\end{array}$} & \multicolumn{2}{|c|}{ Before reduction } & \multicolumn{2}{|c|}{ After reduction } \\
\hline & $R_{F}$ value & Color & $R_{F}$ value & Color \\
\hline 1 & 0.89 & Yellow & - & - \\
\hline 2 & 0.59 & Orange & 0.39 & Yellow \\
\hline 3 & 0.27 & Orange & 0.11 & Yellow \\
\hline
\end{tabular}

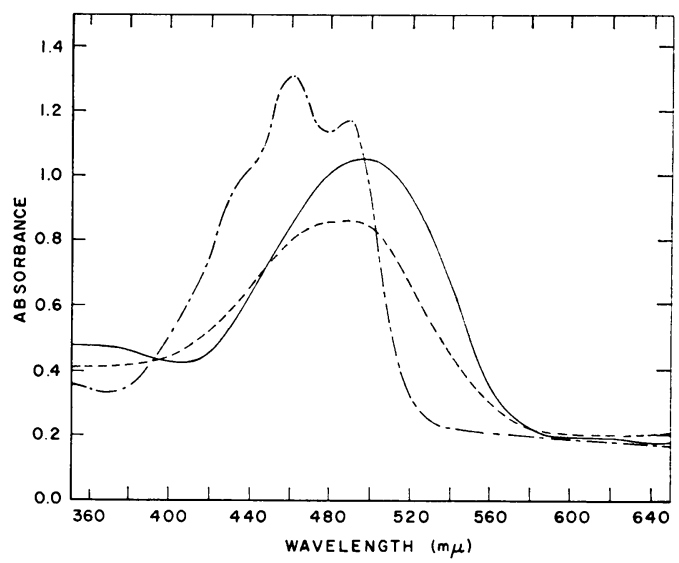

FIG. 1. Absorption spectra of the principal pigment from Micrococcus roseus and derivatives of the pigment. Solid line, pigment in $\mathrm{CS}_{2}$; dashed line, after reduction, in $\mathrm{CHCl}_{3}$; dot-dash line, the reduced pigment after dehydration, in $\mathrm{CHCl}_{3}$. Curves have been shifted on the $y$-axis for clarity.

carotenoids (3). Lack of fine structure in spectra suggested the presence of at least one carbonyl at each end of the molecule in conjugation with the polyene chain $(12,15)$. Carbonyls were also indicated by a peak at $1,745 \mathrm{~cm}^{-1}$ in infrared spectra. The partition coefficient (Table 2) was characteristic of a carotenoid with two carbonyls (14). Tests for epoxides were negative. These data suggested that the pigment was canthaxanthin $\left(4,4^{\prime}\right.$-diketo- $\beta$-carotene, Fig. 2$)$. Upon treatment with iodine in hexane, the absorption maximum decreased 5 to $9 \mathrm{~m} \mu$, indicating the presence of all-trans isomers.

After treatment with $\mathrm{NaBH}_{4}$, the pigment was less mobile on $\mathrm{CaCO}_{3}$ thin-layer chromatography plates (Table 1 ), indicating reduction of carbonyls to more polar hydroxyl groups. The partition coefficient (Table 2) indicated that the reduction product had two hydroxyl groups (14). After $\mathrm{NaBH}_{4}$ treatment, spots on thin-layer chromatography plates were yellow (Table 1), and absorption spectra of the reduced pigment (Fig. 1, Table 2) were typical of $\beta$-carotene (12). 
TABLE 2. Absorption maxima and partition coefficients of the principal pigment of Micrococcus roseus and of derivatives of the pigment

\begin{tabular}{|c|c|c|c|c|c|}
\hline \multirow{2}{*}{ Treatment } & \multicolumn{4}{|c|}{ Absorption maximum $(\mathrm{m} \mu)$ in } & \multirow{2}{*}{$\begin{array}{c}\text { Partition } \\
\text { coefficient ( } \% \\
\text { hypophasic) }\end{array}$} \\
\hline & $\mathrm{CS}_{2}$ & Hexane & $\mathrm{CHCl}_{2}$ & Ethyl alcohol & \\
\hline $\begin{array}{l}\text { None } \ldots \ldots \\
\text { Reduced . . . . . } \\
\text { Reduced and dehydrated . }\end{array}$ & 498 & 470 & $\begin{array}{c}479 \\
(435),,^{b} 462,482 \\
478-486^{a}\end{array}$ & $\begin{array}{c}473-478^{a} \\
(434),{ }^{b} 455,476\end{array}$ & $\begin{array}{r}54-56 \\
88-89 \\
5-11\end{array}$ \\
\hline
\end{tabular}

${ }^{a}$ Varied from experiment to experiment.

${ }^{b}$ Parentheses indicate a shoulder, rather than a distinct peak.

They were also typical of isozeaxanthin $\left(4,4^{\prime}\right.$ dihydroxy- $\beta$-carotene), the expected reduction product of canthaxanthin, since addition of hydroxyl groups to $\beta$-carotene has very little influence on the shape of spectra or the position of absorption maxima (3). Displacement of the principal absorption maximum upon reduction (17 $\mathrm{m} \mu$ in $\mathrm{CHCl}_{3}$, Table 2) was also consistent with reduction of two conjugated carbonyl groups to hydroxyls. Reduction of two nonconjugated $\left(3,3^{\prime}\right)$ carbonyls or one conjugated and one nonconjugated $\left(3,4^{\prime}\right)$ carbonyl would have resulted in a smaller decrease in the wavelength of the principal peak (3). Infrared spectra, however, showed a small peak at $1,745 \mathrm{~cm}^{-1}$.

When the reduced compound (isozeaxanthin) was dehydrated, the product had an absorption spectrum with a single broad maximum, and the spectrum was slightly asymmetrical. The absorption maximum of the dehyrated product was 16 to $24 \mathrm{~m} \mu$ higher than the principal maximum of the reduced pigment (Fig. 1, Table 2), suggesting that a conjugated carbonyl and a conjugated double bond had been introduced by $\mathrm{HCl}$ treatment. The dehydration product also had a partition coefficient (Table 2) typical of a carotenoid with one carbonyl (14). Infrared spectra showed a prominent peak at $1,745 \mathrm{~cm}^{-1}$. Upon treatment with $\mathrm{HCl}$ in $\mathrm{CHCl}_{3}$ (3), isozeaxanthin yields $3^{\prime}, 4^{\prime}$-dehydroechinenone (4-keto$3^{\prime}, 4^{\prime}$-dehydro- $\beta$-carotene).

These data indicated that the original pigment was canthaxanthin (Fig. 2). A sámple of canthaxanthin was provided by Denis L. Fox (Scripps Institution of Oceanography, La Jolla, Calif.). When pigment from $M$. roseus was cochromatographed with canthaxanthin on $\mathrm{CaCO}_{3}$ thin-layer chromatography plates, a single spot was observed. The two pigments could not be distinguished on the basis of their absorption spectra.

Canthaxanthin does not exist in $M$. roseus as an ester, since saponification could be omitted without altering the properties of the pigment.

Canthaxanthin was first isolated from the mushroom Cantharellus cinnabarinus by Haxo

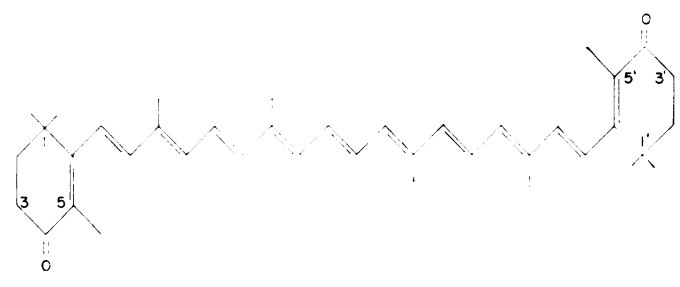

FIG. 2. Structure of the all-trans isomer of canthaxanthin (4, $4^{\prime}$-diketo- $\beta$-carotene).

(8). Its structure was confirmed by Petracek and Zechmeister (15). It has since been reported in flamingos (4), hydra (13), and brine shrimp (11). It may be present in many other organisms, particularly in view of the isolation of unidentified keto-carotenoids from such sources as a water mite (7), a euglenoid (6), and a Flexibacter (5). To our knowledge, this is the first report of canthaxanthin in a bacterium.

\section{ACKNOWLEDGMENTS}

This investigation was supported by Public Health Service grant AI-05421 from the National Institute of Allergy and Infectious Diseases, and by undergraduate research grants from the Cancer Association of Greater New Orleans (to A. M. S.) and the Louisiana Heart Association (to H. W. M. and A. M. S.).

\section{Literature Cited}

1. COONEY, J. J., AND O. C. ThIERRY. 1966. A defined medium for growth and pigment synthesis of Micrococcus roseus. Can. J. Microbiol. 12:8389.

2. Curl, A. L., and G. F. Bailey. 1961. An improved test for carotenoid epoxides. Agr. Food Chem. 9:403-405.

3. Davies, B. H. 1965. Analysis of carotenoid pigments, p. 489-532. In T. W. Goodwin [ed.], Chemistry and biochemistry of plant pigments. Academic Press, Inc., New York.

4. Fox, D. L. 1962. Metabolic fractionation, storage and display of carotenoid pigments by flamingoes. Comp. Biochem. Physiol. 6:1-40.

5. FoX, D. L., AND R. A. LewIN. 1963. A preliminary study of the carotenoids of some Flexibacteria. Can. J. Microbiol. 9:753-768. 
6. GreEN, J. 1963. The occurrence of astaxanthin in the euglenoid Trachelomonas volvocina. Comp. Biochem. Physiol. 9:313-316.

7. Green, J. 1964. Pigments of the Hydracarine Eylais extendens (Acari; Hydrachnellae). Comp. Biochem. Physiol. 13:469-472.

8. Haxo, F. 1950. Carotenoids of the mushroom Cantharellus cinnabarinus. Botan. Gaz. 112:228232.

9. Jungalwala, F. B., and H. R. Cama. 1962. Carotenoids in Delonix regia (Gul Mohr) flower. Biochem. J. 85:1-8.

10. Karrer, P., AND E. JUCKer. 1950. Carotenoids. Elsevier Publishing Co., Amsterdam.

11. KRINSKY, N. I. 1965. The carotenoids of the brine shrimp, Artemia salina. Comp. Biochem. Physiol. 16:181-187.
12. Krinsky, N. I., AND T. GoldSMITH. 1960. The carotenoids of the flagellated alga, Euglena gracilis. Arch. Biochem. Biophys. 91:271-279.

13. KRINSKY, N. I., AND H. M. LenHOFF. 1965. Some carotenoids in hydra. Comp. Biochem. Physiol. 16:189-198.

14. Petracek, F. J., And L. Zechmeister. 1956. Determination of partition coefficients as a tool in pigment analysis. Anal. Chem. 28:1484-1485.

15. PetraceK, F. J., AND L. ZeChmeister. 1956. Reaction of $\beta$-carotene with N-bromosuccinimide: the formation and conversions of some polyene ketones. J. Am. Chem. Soc. 78:1427-1434.

16. Wallcave, L., and L. ZechmeIster. 1953. Conversion of dehydro- $\beta$-carotene, via its boron trifluoride complex, into an isomer of cryptoxanthin. J. Am. Chem. Soc. 75:4495-4498. 